\title{
Global Security and International Migration: Intolarable Weight of the Other in the Global Village Lale Şeyda Gülsoy ${ }^{ \pm}$
}

\begin{abstract}
The aim of this research is to mirror the reflection of Human Trafficking in the Turkish media in the context of "Global Security, International Migration and Otherness". The starting point of the reasons for the increase in human trafficking and the ends of which have survived to the present day is accepted as October 11 terrorist acts due to its shocking effects. For this purpose, the news headlines selected from the newspapers such as Cumhuriyet, Zaman, Radikal, Akşam, Milli Gazete and the period between 2001 and October 2018 were analyzed through discourse analysis. In the conclusion part of the study, the concept of "Peace Journalism" is a new form of discourse has been pointed out. Because Human Trafficking is not just a crime. It is also a major human rights violation. With wars, the new conditions of globalization, ethnic conflicts and poverty, this danger is growing rapidly. However, human traffickers do not receive enough punishment despite the crime they have committed. Even the fate of the victims is not known, news about them can not find as much space as necessary in the media. It's an indisputable truth that there is a need for legislations in order to protect human trafficking victims all over the world. The media should begin to develop a new language in the news for trafficking victims, immediately. The construction of this new language will lead to new and important results for the protection of victims of trafficking.
\end{abstract}

Keywords: human trafficking; global security; peace journalism; globalization; otherness.

\section{Introduction}

\section{What Is Globalization?}

Globalization is seen as the last point where capitalism comes. This process has caused to radical changes in economic structures and social life. According to Veysel Bozkurt ${ }^{1}$, the number of economic crises and military interventions is increasing in the globalizing world. Because of these crises and interventions, people have to struggle to survive in very difficult conditions in their own countries or to travel to other countries in hopes of finding a more humane life.

The key word in the global world is "flow". Knowledge, capital, people and objects can easily spread from country to country with this flow reason. Everything is intertwined and the distinction between "inside" or "outside" or "foreign" and "indigenous" is unclear. However, somehow human rights or democracy issues can not take the share this fluid state sufficiently.

\footnotetext{
${ }^{ \pm}$Lale Şeyda Gülsoy, WEC Academy Country Programme Representative, İstanbul, Turkey. E-mail: laleseyda.gulsoy@wechub.org.

${ }^{1}$ (Bozkurt 2000:188-192).
} 
However, human rights are a kind of "value" and this value should cover all mankind. So any violation in this area should be perceived as "global" and not "local". In this fluid world where borders have lost their old power, everything is very uncertain, risk is everywhere. The World Bank argued that in the global world, national economies would integrate with each other, the economies of developing countries would grow and the gap between the rich and the poor would be covered. However, events have not developed in this way. Barriers in front of the elites have been continuously reduced. Barriers in front of other people have increased. This global climate of inequality has also led to a global crisis of confidence.

According to Kemal Sayar ${ }^{2}$, this "mobility" or "flow" in the global age is subject to a sequence with Bauman's ${ }^{3}$ expression. For the group that is described as the inhabitants of the first world, the borders are insignificant. For this reason, the inhabitants of this world can easily travel where they want. For the inhabitants of the second world, the border lines are thicker. Moreover, the nature of the journeys these people experience and the results of these journeys are quite different from those of the inhabitants of the first world.

\section{Power of Fear in the Global Village}

According to Cengiz Erengil ${ }^{4}$, with "Industrial Revolution", societies had passed through a renewal process and became "Industrial Society". The basic model of this new society is "modernism". At the turn of the 21st century, this time the "Information Revolution" had taken part its place on the stage of history. The society began to move towards a new cultural structure called "Postmodernism". In the roots of information society and post-modernism, we can see the "globalization" process, that will bring the world to the brink of a new wave of change. Modern societies of the Industrial Revolution believe in a strong Enlightenment idea. According to this thought, mind, science and technology will progress much and one day mankind will rule the whole world. Descartes' concept of "Cogito"5 is the essence of the idea of Enlightenment. Hegel's concept of "Absolute Tin"6 is based on this idea. "Absolute Tin" is presented as "the only valid and universal reason" to all mankind. This criterion of the idea of enlightenment has accepted as a determinant of the development processes of all

${ }^{2}$ (Sayar from Bauman 2001:79-94).

${ }^{3}$ (Bauman 1999).

${ }^{4}$ (Erengil 1998:42).

5 "Cogito" is a Latin word, a concept of the Descartes Philosophy and means "Being".

6 "Absolute Tin" is a concept of Hegel Philosophy, "Cogito" in Descartes Philosophy is "Absolute Tin" in Hegel Philosophy. 
countries and cultures. Through this criterion, other societies and cultures have adopted a certain classification in the long run. Discourses such as developed countries or third world countries are thought patterns that emerge through these criteria. Thus, Enlightenment Thought has created its own "others".

In the words of Vehbi Bayhan", the promise the Age of Enlightenment that can control everything in the world has never been realized. Even with the terminology of Giddens, the world is sliding through from our hands. Industry or Information Society is now a Risk Society. "Risk Society" is a concept used by German sociologist Ulrich Beck. This concept has developed by Antony Giddens and describes the new situations that the global world faces in political, social, economic and cultural terms. With Beck's expression, in the 20th century, concepts such as "multitude", "adjacency", and "duality" have begun come to the fore. This "multilayeredness" has increased the turmoil in the world. The boundaries are being tried to be protected on the one hand, while the flow that melts the boundaries can not be stopped at all. This fuzzy process has increased the feeling of fear even more. Globalization is a "adjacency state" has also created the cornerstone of uncertainty. The uncertainty that is one of the basic fears of mankind has created a kind of "blind spot" that excludes strangers and causes the ground of sense of belonging to shift. However, the future is always uncertain and uncertainly risks possibilities within it. These risks are some warning signs. However, if there are too many warning signs on the way we walk, then our ability to move is narrowed. This is another kind of aura. In such a case, the best solution is to avoid all the things and people that are likely to be at risk and danger.

According to Vehbi Bayhan ${ }^{8}$, we must to go to the source of living before and after September 11 in order to undertand all these approaches. The September 11 attacks are a "global terrorist" action and targeted "polyphony" and "multinational tolerance", not only twin towers. The aftershocks of this great tremor are still ongoing. In a global world, the distinction between "us" and "others" has become increasingly evident. Humans hide behind the security barriers to avoid encountering with the stranger. In fact, these barriers have roots in people's minds. For this reason, people have moved away from the idea of sharing the world with other people.

After September 11, 2001, two different state models were emerged. In the model of "state of surveillance", the security motivation was dominant

\footnotetext{
7 (Bayhan 2002:188-201).

8 (Bayhan:188-201).
} 
motivation. Universal values such as human rights and democracy easily be sacrificed for this motivation. The hatred of strangers or the others was a strong thought in this structure. In the "cosmopolitan state model", the difference of "other" was not a threat, living together was precious. After September 11, in these two models, the thinking style of what is called "fundamentalists" has risen in popularity. According to this way of thinking, all foreigners considered to be threats. Countries and people hided behind thick and hard shells to deal with this threat. These thick and hard shells worked up the inequality and injustice. With Vehbi Bayhan's statement, all societies and cultures have become aware of each other in a global world, and so, inequalities have become more transparent. Global economic inequalities created a skeptical mood in developing and ever-developing countries against one-dimensional cultural hegemony and these structures, which prepared the ground for political conflict and contained the risk factor, deepened the distinction between "us" and "other".

With Zühtü Arslan's ${ }^{9}$ expression, the new security concept of September 11 was built on friendly-enemy separation. Immediately after the terrorist attack, US President Bush said, " "Either you are with us or you are with terrorists". These words are based on the declaration of politics based on friendly-enemy separation. Now there is 'us / friends' on one side and 'them / enemies' on the other. Following the September 11 events, the "security state" mentality based on violence has climbed. According to this new understanding, all kinds of opposing sounds can be silenced under the name of preventing terror. This understanding has damaged the human rights the most and put forward the "power of the fear" after the September 11. People have even preferred to suspend even their own rights and freedoms with fearful effect. Authoritarian governments have fired fear even more and have been able to maintain the continuity of their own authorities. This situation is best explained via Horkheimer's mataphor "the eclipse of reason"10. In the words of Michel Foucault, ${ }^{11}$ the mind is the surface of life for power. So, the power legitimizes itself through the mind of the modern subject. In this context, according to Zühtü Arslan, many prejudices have been applied to the minds of modern individuum after September 11, and these prejudices have helped to keep alive the distinction between the "us" and "other" in minds.

According to Sibel Karaduman 12 , the relationship between "us" and "the other" in the global world is not a mutual and integral kind of relationship.

\footnotetext{
${ }^{9}$ (Arslan 2006:125-129).

${ }^{10}$ Marx Horkheimer criticizes Western thought in his book "The Eclipse Of Reason".

${ }^{11}$ (Arslan from Foucault 2006: 156).

12 (Karaduman from Hall 2010: 2888).
} 
On the contrary, there is conflict in the source of the relationship. So this is not a possibility, it is a danger. According to Stuart Hall, the relationship between "us" and "the other" is similar to that of the key and the lock, and they complement each other like key and lock. For this reason, when we exclude "other", at the same time we exclude ourselves. Nevertheless, after the terrorist incidents of September 11, the voice of "others" began to rise further. Now all the others are seen as "dangerous strangers."

\section{Human Rights: Blind Street of Global Village}

In today's global world, a nation's issue of human rights does not concern only that nation. Because human rights abuses in our border neighbors can threaten the peace of the world at large scale. For this reason, human rights violations are a matter of politics and security at both national and global level ${ }^{13}$. In the name of human rights violations, national forces have lost their old sanctions. Organizations such as the United Nations Security Council, the European Union, the Council of Europe and the Organization for Security and Cooperation in Europe have begun to pay more attention to issues such as democracy, human rights and minority rights. While the people of the global world are experiencing mass migration, they acknowledge that this problem is not only regional. However, the threat and widening of the problem has not sufficiently recognized.

Globalization is like a spider web that surrounds the whole world. In this world, all countries are in dependence relation to each other. For this reason, a development in any country affects other countries as well. The attitude displayed in the name of democracy and human rights in a country can not be regarded as a matter of concern only to that country and the citizens of that country in a global world. Because in this new world, the lines between the national field and the international field are uncertain. The issue of human rights is literally "on the knife-back" at a pitch between these two fields.

\section{"Otherness" in the Global World and Reflections in the Media}

All ideologies in the world express themselves through their language and symbols. This language, selected words, phrases, forms of expression, the way of speech used for the transmission of this language are constructed to serve the mainstays of ideology.

${ }^{13}$ (Specialization Commission on Globalization Report 2000: 69-72). 
With Van Dijk's ${ }^{14}$ approach, the media decides which news actors and which topics to bring forward. The media sets the agenda and the boundaries of the agenda.

The media regenerates the dominant ideology, setting the agenda and boundaries of the agenda. The media use emotions such as anger and hate and transforms these feelings into a weapon for groups called "the other". That is, the frame that the mainstream media defines as "us" is determined by the dominant ideology. With this framework, the outline of hate speech is determined.

The power of defining the events of the media consists of a series of practical and serves the functioning of the ideological process. All these practices name the events and classify. Thus, it can be determined by the media which event will come forward or which will be shelve. To sum up and Hall's statement, ideology is not the message itself. Ideology contains the secret codes of some kind of coding system. Ideologies consist of a set of semantic rules. These rules organize images and concepts and determine their function. Whereas the factions of ideology live unaware of these semantic rules that are at the root of their views.

In other words, according to Van Dijk ${ }^{15}$, there are "unspokens" or "implicities" as much as they are in the texts in the media. These implicities may be saying much more between the lines. For example: In the news texts of right-wing publications, "illegal" expression are used when referring to refugees or immigrants. This expression associates people and their actions with crime and directs social convictions. Thus, immigrant and crime are perceived in people's minds together .

Again, according to Van Dijk, ${ }^{16}$ when we examined news texts about groups such as minorities, immigrants and third world countries, we can see that these news do not take place in the scope of important news in dominant media. These groups live very far from the aims and rules of the dominant structure, which they call "us". They can not exist on their own, they often create problem. They use the resources of dominant construction and become a burden to dominant construction.

The media creates both a new reality with the topics it chooses from within reality and reproduces all the definitions of this reality. This process of meaning production is based on the continuation of ideology through language and signs.

14 (Küçük from Van Dijk: 2005:350).

${ }^{15}$ (Van Dijk 1991:1-5).

${ }^{16}$ (Küçük from Van Dijk 2005: 351-52).

Copyright@ 2018 BORDER CROSSING @ Transnational Press London 


\section{Discussions and Findings in Human Trading News: The Invisible Face of the Ice}

\section{Method and Technique}

In this research, news titles of the newspapers were analyzed through discourse analysis. Discourse analysis is a method that easily reveals negative judgments about the "other". Van Dijk bases this method on two basic solutions, Macro and Micro analysis. Macro analysis is based on news titles. Because news titles are a summary of the news in a sense. Micro analysis focuses on word choice. The word choices in the news titles are the mirror of the ideological perspective.

\section{Sample}

In the research, the news of 5 journalists from the printed press Cumhuriyet, Zaman, Milli Gazete, Radikal and Akşam - between 2001October 2018 have been examined in the news about "Human Trafficking" in general and "refugee" and "immigration" in particular. Research has also been conducted in the Internet archives of newspapers and the results of these investigations have been included in the field of research. Key words of "Refugee", "Illegal Migration", "Illegal Immigrant", "Asylum Seeker", "Smuggling of Migrants", "Human Trafficking" and "Human Trafficker" were used in newspaper searches related to Human Trafficking.

\section{Evaluation of Research Results}

Before commenting and analyzing the news, the table below shows the numbers of news stories about Human Trafficking, which took place in newspapers between 2001-October 2018.

Tablo 1. Distribution of Human Trafficking News Between 2001-October 2018

\begin{tabular}{|l|r|r|r|r|r|r|r|r|r|}
\hline Ylllara Göre Dağılım & 2001 & 2002 & 2003 & 2004 & 2005 & 2006 & 2007 & 2008 & 2009 \\
\hline Cumhuriyet & 53 & 33 & 34 & 29 & 6 & 27 & 45 & 19 & 5 \\
\hline Zaman & 6 & 17 & 15 & 33 & 51 & 78 & 123 & 178 & 87 \\
\hline Radikal & 68 & 69 & 40 & 32 & 40 & 57 & 64 & 32 & 55 \\
\hline Akşam & 40 & 34 & 11 & 11 & 11 & 28 & 15 & 7 & 22 \\
\hline Milli Gazete & & & & & 14 & 10 & 33 & 52 & 33 \\
\hline
\end{tabular}


564 Global Security and International Migration

\begin{tabular}{|l|r|r|r|r|r|r|r|r|r|}
\hline Ylllara Göre Dağllım & 2010 & 2011 & 2012 & 2013 & 2014 & 2015 & 2016 & 2017 & 2018 \\
\hline Cumhuriyet & 6 & 17 & 11 & 11 & 18 & 62 & 21 & 114 & 230 \\
\hline Zaman & & & & & & & & & \\
\hline Radikal & 3 & 10 & 10 & 8 & 13 & 145 & 15 & & \\
\hline Akşam & 1 & 7 & 10 & 19 & 9 & 38 & 47 & 116 & 94 \\
\hline Milli Gazete & 8 & 5 & 12 & 5 & 20 & 22 & 64 & 163 & 96 \\
\hline
\end{tabular}

\section{Macro Analysis}

Macro Analysis is a method that reveals which topics are more prominent in news titles. In this research, a discourse analysis was carried out by assuming that the topics that are most emphasized in a news title are the most important ones. In the context of Macro Analysis, the newspaper which was first examined is the Cumhuriyet. Examples of news titles about the Human Trafficking in Cumhuriyet Newspaper are "60 Illegal Immigrants Disappeared": 27 November 2002, "62 Illegal Immigrants Caught In The Truck Bed" 15 May 2005, "105 Illegal Immigrants Caught In The Aegean Sea": 15 October 2008, "The Boat Which Carrying Of The Illegal Immigrant Sinked: 22 People Disappeared": 16 January 2011, "The Mediterranean Has Been Burial Chamber For 2 Thousand 365 Immigrants": 24 August 2015, "63 Illegal Migrants Caught in Death Journey": 5 June 2017, "There Was a Total of 53 Illegal Immigrants in a 15 Seater Minibus": 29 September 2018. These news titles examples provide information about the situation of immigrants and often use numerical data for this purpose.

Other Human Trafficking news titles inform us about the reports, designs, measures and legal regulations that are accepted in the fight against Human Trafficking. These examples are "Protocol Against Human Trafficking": 30 June 2004, "Illegal Immigrant Report From The United States": 10 May 2011, "Immigration Law Is On Its First Serious Exam At The US Congress": 9 May 2013, "A Very Important Decision From The EU": 23 April 2014, "Syrian Refugees in Turkey with a Stunning Related Research": 21 July 2017 and "Trump's Decision Concerning Migrant Children": 20 June 2018

Although the Cumhuriyet newspaper news titles related to human trafficking immigration and the refugee issue are often presented in numerical datas, the news titles in the Cumhuriyet Newspaper emphasizes social or political aspects of the Human Trafficking issue. Examples of such news titles are "Internal Agenda Of The EU Is Human Trafficking": 18 June 2002, "10 Million Refugees In The World": 20 June 2007, "Slavery's New Name: Human Trafficking": 18 July 2011, "Human Trafficking": 2 July 2012, 
"Sale Immigrant Children In Turkey": 9 August 2015, "Syrian Refugees Are A National And Social Security Issue": 14 July 2016 and "Merkel: Migration can Determine the Future of the EU": 28 June 2018.

The second newspaper examined is the Zaman Newspaper ${ }^{17}$. Only numerical information is given about immigrants in these news titles. However, each numerical data actually refers to a human story. This is as if the truth is almost forgotten such as "23 Illegal Immigrants Caught In The Flat Boat" and "106 Persons Which Entering Illegal Ways To Turkey Took Into Custody".

We can also see in the Zaman Newspaper that news titles containing expressions related to Human Trafficking's situation in Turkey are in Cumhuriyet Newspaper. Examples of these news titles are "38 Gang Organizes Human Trafficking In Turkey" and "Turkey Has Been Raised To The Upper Group In The 2005 Annual Report On Human Trafficking".

The methods used by human traffickers have been put on the table such as "The Last Point In Human Trafficking: The Sea Train" and "Mind-Blowing Methods From Human Traffickers".

The news titles like "Illegal Immigrants Will Not Be Accepted Suspect, They Will Be Accepted Victim" refer to the latest legal regulations on Human Trafficking.

The social or political aspects of the Human Trafficking issue are not mentioned in the news titles in Zaman Newspaper. Let me examine the news titled "Gendarmerie Caught 29 Irakian And Afgani Illegal Immigrant". People in many countries are experiencing social and political developments and these developments are causing international migration. However, this title only approaches the number and the nationality of illegal immigrants.

Radikal Newspaper ${ }^{18}$ is the third newspaper examined in this research. The social or political aspects of human trafficking in the Radikal Newspaper are also highlighted in the news titles. Such news titles are "Seeking Solutions For Irakian Refugees" 27 July 2007, "Millions Of Refugees In Pakistan" 12 May 2009 and "Refugee Children Facing Many Problems in Public Schools": 29 September 2015.

\footnotetext{
17 Since the Zaman Newspaper's website has been closed and access to the journal's archive has been blocked, since 6 March 2016, it has not been possible to reach the old news sources of the newspaper. For this reason, only the news from 2001 to 2009 have been taken into consideration( The data between 2001 and 2009 were reached before the archive was closed, but no date information is available on these news).

1821 June 2014: Radikal Newspaper received a decision to broadcast on the digital platform. 22 May 2016: Radikal Newspaper's website is down. 9 November 2016: The digital archive of the Radikal Newspaper has been deleted. 22 March 2016: radikal.com.tr was closed.
} 
Within the scope of the research, the fourth newspaper is Akşam newspaper. In the news titles of the newspaper, it is seen that the problem of human trafficking was mostly revealed with drama element. The main purpose of the drama is not to express the problems of immigrants, but to attract the attention of the reader through the drama element.

When we looked at the results of the news analysis of the fifth newspaper which called Milli Gazete, we can see that refugees and immigrants are almost a numerical data in almost every news titles. The situation of refugees and immigrants is tried to be expressed in the news titles in general. However, no determination is made for the reasons of this general situation or for the solution of this situation. Immigrant and refugee news titles seem to be talking about an ordinary situation.

\section{Micro Analysis}

Word selection and sentence structures of news titles were analyzed by microanalysis. Word choices and sentence structures, in a sense, are pictures of the ways that news titles used for persuasion.

"Berlusconi Is Sending Immigrants Back": 9 April 2011, "Wire Mesh Worked At The Turkish Greek Border": 9 February 2013, "Request For Emergency Status For Immigrants In Greece": 3 September 2015 and "Put up a Wall to the Sahara Desert": 20 September 2018. When we analyzed news titles of the Cumhuriyet Newspaper through micro analysis, we can see traces of negative attitude displayed against immigrants. According to this approach, immigrants create problems and they break the existing order.

In the news titles about human trafficking, words such as "drama", "tragedy", "destruction", "death" are mostly used and the dramatic aspect of the subject is emphasized. Examples of these news titles are "Illegal Immigrants Destruction In Greece": 4 Person Died": 23 November 2010, "Immigration Drama In The Mediterranean: 54 Person Died": 11 July 2012, "The Tragedy Of The Immigrants In Desert": 29 October 2013, "Illegal Immigrant Tragedy": 18 April 2015, "Another Immigrant Destruction: 9 Person Died(4 Children)": 2 February 2016 and "Tragedy in Cyprus: 19 Dead": 18 July 2018.

When we analyzed the news of the Zaman Newspaper through micro analysis, we can see: "The Number Of Illegal Migrants Is Increasing". In this title, the immigration is described as "illegal". However, the illegal word used here is different from the intended use and contains a negative implication $^{19}$. This implication associates to immigrants and refugees with

${ }^{19}$ (Van Dijk: 1991).

Copyright@ 2018 BORDER CROSSING @ Transnational Press London 
the concept of crime. Some negative implications are also for a country. It may seem that there is not a big difference between the Greece Police and the Greek Police qualifications in terms of meaning. The word "Greek" is not only an abbreviation. There are negative implication in the essence of this word. "Immigrant Hunt Of Greek Police Concluded With Death". In this title, it is necessary to pay attention to the negative implication of the Greek police and the definition of "immigrant hunt". Because the action of the Greek police to catch the immigrants is likened to "hunt". Whereas people never get"hunted". If they break the law, they just "get caught". The double-headed negative implication of this news title is directed at Greek Police and immigrants.

"When Pilots Do Not Fly To Somalia, Immigrants Remained Unsold". In the beginning of this news title, the news language problematical. Because if the immigrants are not sold, they are not the commodities that will cause the merchant to lose money.

The sentences formed by the act of being caught are frequently seen news titles. They are used in news titles related to both human traffickers and migrants. Examples of such news titles are "27 Illegal Immigrants Caught In Dikili", "88 Illegal Immigrants Caught in Ankara" and "85 Illegal Immigrants Caught In The Truck Bed".

In the news titles, the words of disaster, drama and brutality highlight the drama. News titles such as "Immigrant Tragedy In The Indian Ocean", "Savagery In The Flatbed Trailer" and "The Suffering Of Refugees Do Not End" do not try to show that the Trafficking issue can lead to dramatic results. On the contrary, such expressions make the concepts of drama, savagery or tragedy ordinary.

"Immigrant Violation in the Aegean Sea in Amnesty International Agenda": Under this heading on the abandonment of Greek immigrants to the Aegean Sea, Greece's illegal immigrant violations are underlined. Turkey is a preferred country for refugees as it is in the news title of "The Refugee Who Gave Birth In The Truck: I Want To Enlarge My Baby In Turkey". When we combine the two titles of news stories, we can see clues of negative implication about Greece.

When we examined Radikal Newspaper with micro analysis, we can see that some news titles carries a negative implication. The negative implication of the "Immigrant Hunt Of Greek Racists" dated 11 May 2009 is against Greece and accuses Greece of being a racist. The act of caught devoted to illegal immigrants is expressed by "hunting". In Radikal Newspaper, we can also encounter news titles about Kurdish refugees. In the "Kurdish Illegals In Jakarta" dated 12 November 2003 only the word "Illegal" is used instead of the immigrant in the news title. So, in fact, 
Kurdish immigrants are being blamed. In the title "A Kurdish Influx Of Immigrants To The Italian Coasts" dated 2 September 2001, the word "influx" is important. Because the word "influx" may indicate the movement of a large group of people, or it may mean a disturbing element for foreign lands.

In the news titles such as "Illegal Immigrants In The Aegean": 5 May 2014, "Illegal Drama In Marmaris: Boat Which Carried 18 People Crashed"; 7 February 2015 and "Tragedy Of Syrian Refugees In The Aegean Coast: 6 Dead": 29 November 2013 life struggles of refugees and immigrants have been expressed in words such as "drama" and "tragedy".

When we analyzed the Akşam newspaper with micro analysis, we can still see that the word "Illegal" is mentioned by immigrants in the news title "The 31 Illegal Immigrants Caught In Kırklareli" dated 26 October 2016 and "The Boat Which Illegal Immigrants Transported Sank in Edirne" dated 13 February 2018.

"The Face Of Human Traffickers: Death": 15 October 2013, "The "Refugee Century": 18 September 2015 and "Where Are The 10 Thousand Refugee Children?": 1 April 2016: All these news titles are meant to cause a sensation.

In the news title "Lost 13,000 Refugees In Greece": 8 December 2016, the reason for the disappearance of refugees is uncertain, so there is a negative implication for Greece in this title.

When we looked at the Milli Gazete in terms of micro analysis, we can see that immigrants are mentioned as "Illegal" in the news titles such as "176 Illegal Catched By Security Forces": 18 May 2008, "51 Illegal In Edirne": 27 April 2010 and "39 Illegal Immigrants Caught in Çanakkale": 4 January 2018. With the expression of Van Dijk, this is a "negative implication"20 and contains more than a simple abbreviation.

Refugees and immigrants are only a matter of numerical data in these new titles such as "In The World, 8 Million Refugees Are Unemployed And In Bad Situation": 17 June 2005, "The Explosion Of The Illegal Was Experienced: 40 Thousand": 1 January 2008 and "Last Year Total 50 Thousand Illegal Immigrants Caught in Edirne": 3 January 2018.

According to the title "Places Where Refugees Live Looked Like Waste Bin": 5 January 2016, immigrants and refugees are creating problems where they live. Immigrants are "Illegal" in the news titles such as "Illegal Immigrants Released From Bus Trunk Baggage": 16 April 2014, "291 Illegal Immigrants Caught In 3 Days In Aegean": 29 June 2015 and "Illegal Chinese

${ }^{20}$ (Van Dijk: 1991).

Copyright@ 2018 BORDER CROSSING @ Transnational Press London 
Workers Taken In Detention In The Philippines": 5 November 2016. Therefore, they are either "caught" or "taken into custody".

In Turkey, there are no reports on the causes of refugee and immigrant problems in the news titles of Human Trafficking, nor on the resolution of this problem. Immigrant and refugee news titles seem to talk about an ordinary situation. Examples of these news titles are "Becoming Asylum Seeker In Turkey": 27 September 2008 and "Roads Of Migrants Cross In Turkey": 28 January 2008.

In the news title of November 27, 2010 "Giammarinaro: Slave Trade Under The Name Of Illegal Immigration", action carried out by immigrants and refugees is called "illegal". However, the word "illegal" used here is different from the intended use. It relates immigrants and refugees to the concept of crime.

\section{CONCLUSION}

Peace Journalism: We Are All the Same KAYiki! ${ }^{21}$

In a global world, the issue of Human Trafficking is also a global problem. Therefore, the problem of trafficking must be resolved on a global platform. In the course of such a solution, the media should accept the seriousness of the Human Trading issue. Human trafficking is not only a dramatic issue. Immigrants and refugees are not only crowd, not guilty people. There is a new understanding of journalism that is aware of these details in the world and it is called "Peace Journalism".

According to Lee and Maslog 22 , Peace Journalism focuses reconciliation points. When talking about the causes and consequences of conflicts, it does not distinguish people as "good" or "bad", but also adopts an attitude towards resolution. Post-war settings and peace agreements are among the issues discussed by peace journalism. In this new journalistic approach, victims are not identified with numerical data and emotional words. An objective, and moderate news language is essential.

According to McGoldrick ve Lynch $^{23}$, the main principles of peace journalism can be summarized as follows: In peace journalism, there is no conflict between winners and losers. Peace journalist constantly questions the relationship with the reality. A peace journalist deeply examines the policy of violence and a peace journalist avoids ordinary discourses. A peace journalist does not view violence as the only source of news. Explains

21 "Kayiki" is a campaign launched by a group of academics, students, volunteers, documentaries, photographers and refugees from Turkey and Greece to prevent further refugee deaths between the waters of Turkey and Greece.

22 (Lee and Maslog 2010: 86).

${ }^{23}$ (McGoldrick and Lynch 2000: 100-102). 
violence and looks for reasons. For the peace journalist, there are no two groups of people, victims and bad people in the world. Acting with the principle of impartiality and informing people correctly are the main tasks of the peace journalist.

In a global world where borders are not as sharp as the old one, any development in any country can easily affect other countries. Hence, no country can exclude itself entirely from human rights violations. In this case, the Human Trafficking issue, which is a violation of human rights, is not merely issue of some countries, otherwise the world's issue. For this reason, all countries should work together to resolve the issue. Recent researches show that environmental disasters caused by global warming will lead to new and great migration waves, and if measures are not taken, this situation will again benefit for human traffickers.

\section{References}

Arslan, Z. (2006). "New Security Understanding After September 11, Human Rights and Democratic Law Enforcement". Police Science Magazine. Volume: 8. Pg. 125.

Bauman, Z. (1999). "Globalization: Social Consequences". Translated by: Yılmaz A. Ayrıntı Publications.

Bayhan V. (2002). "Risk Society". East West Quarterly Thought Magazine. Year: 5 Issue: 19. Bozkurt, V. (2000). "The Social Consequences of Globalization".

Erengil, C. (1998). "Enlightenment, Reason and Post-Modernism". Magazine of Thought and Reason.

Karaduman, S. (2010). "Structural Transformation of Identities from Modernism to Postmodernism". Pg. 2888.

"Specialization Commission Report About Globalization". Ankara 2000.

Lee and Maslog (2005). "War Journalism - Peace Journalism Differences". In the Book: "Media, Peace and War". In the Article: "Peacekeeping or Journalists Peacefully". Prepared by: Barış Çoban. Pg: 86.

McGoldrick ve Lynch (2000). "How Should Peace Journalism Be Done?". In the Book: "Media, Peace and War". In the Article: "While the Press is Occupying Our Mind, Is Peace Media Utopia?-Approach Over Turkey-Armenia Protocol to the Turkish Press, Peace Journalism Glance". Prepared by: Barış Çoban. Pg: 100-102.

Sayar, K. (2001). "Psychological Dimensions of Globalization". Pg. 79-94.

Van Dijk, Teun A. "Interdisciplinary Analysis of News as Discourse".

Van Dijk, Teun A. "Structures of Discourse and Power". In the Book: "Media, Power, Ideology". Translated by: Mehmet Küçük. 2. edition. Ankara: Ark. Pg. 315-362. 